\title{
Teaching What Is "Real" About Science
}

\section{Critical Realism as a Framework for Science Education}

\author{
Sarah L. Ferguson ${ }^{1,2}$ (D) \\ Accepted: 25 November 2021 / Published online: 14 January 2022 \\ (c) The Author(s), under exclusive licence to Springer Nature B.V. 2021
}

\begin{abstract}
Discourse about public perception of science is often positioned as a dichotomy between trust in scientific evidence and scientists as experts, versus critiques of the limitations of scientific knowledge and a mistrust in scientists as biased professionals and political agents. However, this dichotomy becomes something of a false argument, as our tendency to look for the "right" answer in these arguments often gets in the way of finding a balancing point in which both of these positions could be held in productive tension. The purpose of the present article is to lay out the argument that society can both trust in scientific evidence and question scientific bias in the same space, holding these two seemingly opposite positions in productive tension, and that we should teach students to do the same. Critical realism is presented as an ontology and epistemology to frame science education, and focus on the development of critical scientific literacy by teaching students what is real and what is arbitrary about science. Recommendations for science education are outlined, grounded in critical realism and connected to current education research and principles of the nature of science.
\end{abstract}

\section{Introduction}

In his 2015 focus article "Can we Teach People what Science is Really Like?", Collins ends his essay with the statement "Thank heaven my job is not to teach." The article offers a framework for science and science education grouped around three epistemological waves of thought about science (Collins \& Evans, 2002; named simply wave one, wave two, and wave three) and discusses the challenges of teaching students about scientific knowledge and scientific practice in the classroom setting through these waves. The metaphor of waves provides a starting point in this conversation, but for those whose job it is to teach, there is a need to address the identified challenges of modern science education

Sarah L. Ferguson

fergusons@rowan.edu

1 Department of Interdisciplinary and Inclusive Education, Rowan University, 201 Mullica Hill Road, Glassboro, NJ 08028, USA

2 Department of Educational Services and Leadership, Rowan University, 201 Mullica Hill Road, Glassboro, NJ 08028, USA 
and support the work that science educators take up in trying to teach what science is really like.

In Collins and Evans (2002), wave one science was historically focused in the early 1900 s up to the 1970s, though elements of this paradigm linger into present thinking. Wave one was grounded in positivism and saw scientists as experts, or seekers of truth in the natural world. For science education in this wave, curriculum was written and directed by scientists and professors, focusing on broad science methods and knowledge and not local contexts or ways of knowing. Science in the classroom was designed as a microcosm of real science, intended to train students to be scientists in the future. Wave two science was presented as occurring from the 1970s to the present, grounded in postmodernism and emphasizing constructivist approaches to science education. Expertise of scientists becomes increasingly questioned, understood more and more as biased individuals or agents of politics and industry. Science education in this period is driven by standardized testing and policy requirements, hold overs from a positivist framing. Conversely, science education increasingly allows and prioritizes critiques of science and scientists, while classroom labs and experiments were less focused on training scientists and more on developing practical science knowledge. Finally, wave three science was presented as a more recent shift, starting in the last decade and seeking a balancing point between scientists as experts and a need for accountability and transparency in the professional work of science. While Collins and Evans (2002) do not identify a specific paradigm for wave three, much of their argument can be aligned within the paradigm of Critical Realism, and this framing is presented here with particular focus on the practical application to science education. I argue that science education understood within a framework of Critical Realism should focus on critical scientific literacy as a goal, balancing both non-arbitrary scientific knowledge and arbitrary skills such as critical thinking in the curriculum.

In discussing these epistemological waves of science study, the discourse about public perception of science is positioned as a dichotomy between trust in scientific evidence and scientists as experts versus acknowledging the limitations of scientific knowledge and a mistrust in scientists as biased professionals and political agents (Collins, 2015; Collins \& Evans, 2002). Modern understandings of expertise have shifted, as argued in Collins and Evans (2002) but more extensively in the work of Watson (2020). Changes in communication due to technology, and the impact of social status and positionality on perception, have all impacted how expertise is perceived and subsequently how individuals trust and do not trust "experts" (Watson, 2020). In some ways, this comparison mirrors the epistemological argument between positivism and empiricism on the one hand with a search for universal truth and objectivity (wave one), and postmodernism and transcendental idealism on the other hand with a focus on experiences and an understanding that "truth" is all interpretation (wave two) (Bhaskar, 1998; Collins \& Evans, 2002; López \& Potter, 2005). Of course, this progression in thought is not unique to Collins and Evans (2002) or even science as a field. The concept of scientific revolution was famously argued in Kuhn (1970), and while the metaphor of revolution has been debated extensively, the concept of paradigm shift has carried forward. Collins and Evans (2002) are using the metaphor of waves instead of revolutions to discuss paradigm shifts in science study, and Collins (2015) then applies this metaphor and conception of paradigm shift to science education. From a broad epistemology standpoint, the first two waves in Collins and Evans (2002) and Collins (2015) are positioned as the shift from positivism to postmodernism, and this same shift has been discussed and argued repeatedly in many fields of study (e.g., Good, 1993; Houghton, 2008; Mackenzie et al., 2014). However, this dichotomy becomes something of a false argument, as our tendency to look for the "right" answer in these approaches to science and 
philosophy often gets in the way of searching for a balancing point, in which both of these positions could be held in productive tension. Collins and Evans' (2002) argument for a third wave provides a space for this balancing point, a somewhat newer conception that is still being explored in many fields and what others have classified as dialecticism (Marsden \& Littler, 1999; Mumby, 2004) or critical realism (Bhaskar, 1998; López \& Potter, 2005; Pratt, 1995; Steinmetz, 1998; Reed, 2011).

The same epistemological argument could be applied to science education, giving context to changes in science education over time that align with, and would arguably by precursors to, the waves of change in public perception of science over time. Positivism as an early paradigm for science education did not allow for an understanding of bias and the social impacts on knowledge, limiting our ability to do and teach science in real and meaningful ways. However, if we argue, as wave two science study largely did, that science education should be positioned in a postmodern epistemology, what is our reasoning as to why one individual's claim and experience are any less valid than another individual's? Even if one individual making a claim is a scientist with developed expertise in the topic, and the other is a student in high school developing their foundational knowledge of the topic, postmodernism does not give allowance for hierarchies of expertise or the existence of clearly right and wrong answers, which are essential for developing trust in and understanding of science. If we argue that modern science education practice has moved too far away from a grounding in scientifically supported evidence in the shift towards postmodernism, what follows can therefore provide a framework for the science denial and mistrust we see increasingly in public perceptions of science and scientists (Mackenzie et al., 2014). Connecting an epistemology of science to that of science education is not a direct line, as science education operates as its own field with unique characteristics different from science as a field (Gil-Pérez et al., 2002). Of note, the paradigm shift waves of Collins and Evans (2002) do not easily account for constructivism, an example of a paradigm shift in education and learning that is not as clearly linked to other applied epistemologies (Gil-Pérez et al., 2002; Matthews, 1998). A clear distinction needs to be made here, that constructivism as a theory of learning is not the same thing as an epistemology of constructivism applied to other fields (Gil-Pérez et al., 2002). To clarify, the argument here is that science education curriculum and teaching practices are developed and implemented within the concurrent epistemology of science study; the focus in this article is therefore on the epistemologies of science study and their connection to science education.

The purpose of the present article is to lay out the argument that society can both trust in scientific evidence and question scientific bias in the same space, holding these two seemingly opposite positions in productive tension and teaching students to do the same. Critical realism is specifically presented as an epistemological stance that allows us to function in this tension, giving space for both the empirical reality (what we directly experience of the natural world in any one situation) and the actual reality (the sum total of collective empirical experiences across time and across people) of science in science education (Bhaskar, 1998; López \& Potter, 2005; Scott, 2010). In this work, I will first discuss the shifting paradigms of science and science education and how these might contribute to social trust and mistrust of science. Then, I will present critical realism as an ontological and epistemological lens that gives space to both areas of tension in science education, and discuss how this lens differs from positivism and postmodernism in concept and in application to teaching science. Finally, I will explore the practice of science education that would be possible under a critical realist lens, connecting to recommendations from science education research and the National Science Teaching Association (NSTA) to begin to position this approach in current science education practice. 


\section{Three Paradigmatic Waves of Science Studies}

Though a broad generalization, the three paradigm shifts of science study argued by Collins and Evans (2002) and later connected to science education in Collins (2015) provide a useful framing for an understanding of current perception of science. Like critiques of Kuhn's scientific revolutions, there are clear problems with any metaphor trying to encapsulate the whole of social perception and teaching of a field of study like science. However, in general terms, the metaphor of waves as paradigm shifts is used to discuss the epistemologies of the time in understandings about science and science education, and to capture the changes in how science and scientists have been perceived. One specific challenge with this metaphor is the idea that these waves are non-overlapping or linear in progression, where in reality they are overlapping and create more of an additive progression of ideas as the epistemology of wave one has not disappeared in subsequent waves, but rather been overtaken and intermingled with the new epistemologies of later waves.

The discussion is provided here as context and groundwork for the foundational argument of this paper that critical realism can serve as ontology (what can be known) and epistemology (how humans come to know) for what would be understood as wave three science. The intention is not to provide a complete overview of the history of science or science education in these waves, but rather to use this framing from Collins and Evans (2002) as a model for framing paradigms shifts in science study and science education. Additionally, this is not an argument for what constitutes the nature of science, nor is it a review of the literature on the philosophy of science. Others have engaged extensively in that work, and readers are referred to the works of David Bloor, Ian Hacking, Bruno Latour, and Ilkka Niiniluoto as philosophers of science. Other resources are recommended for readers interested in further exploration of the history of science (see Kuhn, 1970; Marks, 1984; Pyenson \& Sheets-Pyenson, 1997), history of science education (see Brush, 1989; DeBoer, 1991), and the three waves of science (see Collins \& Evans, 2002, 2003; Owens, 2011; Wynne, 2003).

\subsection{Positivism in Science Study}

In Collins and Evans (2002), wave one perceptions of science were presented as grounded in empiricism and positivism, searching for objective and universal truth. Scientists were positioned as experts in their field due to their training, and no real question or thought was systematically given to outside pressures or biases that would have impacted the scientist and their exploration (Collins, 2015; Collins \& Evans, 2002). Theorists derived explanations for the natural world, experimentalists tested these theories with data, and lines were rarely crossed between these types and/or between disciplines of science (Collins, 2015). This paradigm is positioned at a peak around the 1950s-1960s, a time of substantial scientific development including the commercial computer and spacecraft, but also the hydrogen bomb and nuclear weaponry. The search for objective truth and advances in science sometimes overshadowed ethics and moral decision making, giving continued space to the eugenics movements and unethical human experimentation like what was seen in the Tuskegee experiments (1932-1972) or on a smaller scale the Stanford Prison experiment (1971). Empirical data was the goal of experimentation and the groundwork of scientific inquiry and discovery, and little focus was given to implications of scientific choices or the possibilities of error and bias in interpretations. 


\subsection{Postmodernism in Science Study}

Wave two science was presented as a paradigmatic shift in academic thought and experimentation around the early 1970s continuing on to recent years, with understandings of science moving away from positivism and towards postmodernism (Collins, 2015; Collins \& Evans, 2002). In this shift, the role of humans and society in science gained attention, and increasingly empirical evidence alone was not sufficient for decision making without also accounting for context, social implications, human biases, and external pressures. Scientists as experts in applied contexts such as the courtroom, politics, and business or industry increased, and with that came new questioning of the scientists themselves as unbiased experts (Bloor, 2000; Collins \& Evans, 2002; Jasanoff, 2009).

While the advances of science into more applied and practical spaces were sometimes positive, examples of biased scientific reporting, such as a pharmaceutical company paying for positive results, or a tobacco company encouraging scientists to not publish negative results that would impact their business, created distrust in science and scientists (Collins, 2014, 2015). With this distrust came an understanding that empirical evidence was susceptible to interpretation, and interpretations could differ between people. As a result, the lines between experts and non-experts became blurred, and concepts of the citizen scientist, or more dramatically YouTube experts, appeared in popular discourse about scientific issues (Brown, 2015; Collins \& Evans, 2002; Funke, 2017; Gauchat, 2015). Climate change research became subject to climate denial, medical science about vaccinations saw an increase in anti-vaxxer opponents, and most recently in the COVID-19 pandemic, public health experts and epidemiologists are positioned against anti-maskers and "China virus" conspiracy theorists (Collins, 2014; Sarathchandra \& Haltinner, 2020; Weinstock et al., 2017).

\subsection{Critical Realism and Dialecticism in Science Study}

Wave three science is presented as a more recent and ongoing paradigm shift in research on science and science education, as society and scientists both attempt to reconcile the value of scientific knowledge and expertise with accountability for the social implications of science and the external pressures that impact scientific work (Collins, 2015; Collins \& Evans, 2002). The ideal presented in this paradigm of science is to support the expertise of scientists in their specializations, while also holding scientists to a high standard of ethics and professional practice (Collins \& Evans, 2002; Watson, 2020). After decades of debate between positivism and postmodernism, critical realism presents an approach to hold these two perspectives in tension with each other. In much the same way that mixed-methods research approaches have gained ground in connecting positivist or post-positivist quantitative methods and constructivist or postmodern qualitative findings, critical realism as a paradigm for science study can be seen as a space to link these understandings into a cohesive and more complex understanding.

In science itself this could include an emphasis on the expertise of scientists in their fields, and recognition of the role of scientific expertise in both scientific discovery and as a social good (Grundmann, 2017). Scientists are called to engage in collaborative discourse with social and political agents, not creating a space where science is inherently political but rather acknowledging that science is a site of politics (Brown, 2015). Recognition in this paradigm of science must also be given to non-scientist expertise and the value of 
practical knowledge in discovery and problem solving (Grundmann, 2017; Watson, 2020). Instead of viewing scientists as either removed, unquestioned experts or biased, untrustworthy agents, I argue that critical realism as a paradigm of science positions scientists as experts in theoretical knowledge that can work together with others in service to the public as well as engaging in basic scientific research.

The public non-expert role in science becomes one of consumer and stakeholder, keeping scientists accountable and maintaining integrity, while also defining who is an expert and who is not (Collins, 2015; Collins \& Evans, 2002; Watson, 2020). Research, especially when it is funded by public dollars, is understood as a form of social or public good (Beebeejaun et al., 2015). Given this understanding, scientists need to account for the social implications and ethical impacts of their research and discussions of their findings (Weinstock et al., 2017). Instead of considering science as doing research on the natural processes or environments in communities, wave three science could ask scientists to do research with communities and share power and decision making in that process (Beebeejaun et al., 2015; Weinstock et al., 2017). Additionally, the non-expert public is called to have a foundational knowledge about science in what is often termed "critical scientific literacy" so they can function as an informed consumer of scientific research and processes (Weinstock et al., 2017).

\section{Critical Realism as Framework}

Critical realism is relatively new to the field of philosophy and is often presented as a response to postmodernism and a critique of positivism (Bhaskar \& Lawson, 1998; López $\&$ Potter, 2005). Presented as both ontology and epistemology, critical realism argues for an ontology of transcendental realism and an epistemology of relativism and rationality in an understanding of the multiple strata of reality and how we as humans interact with and experience the empirical world (Bhaskar, 1998; Scott, 2010). Transcendental realism is a key tenet of critical realism that gives recognition to the tension that exists between objective positivism and postmodernism. Specifically, transcendental realism argues that there is a natural reality, with its own laws and systems that exist regardless of human interaction. Science and empirical experimentation are understood as the human activity that allows us to explore this natural reality. However, human activity in science and exploration should not be understood as a way to know all of natural reality, as we both interrupt nature due to the activities of science, and can only experience one portion of the natural reality in any given empirical activity (Bhaskar, 1998; Bhaskar \& Lawson, 1998). In this way, human activities and explorations in the natural world can be seen from two directions: the intransitive view of reality and the transitive view of human experience (López \& Potter, 2005). The intransitive view of reality understands that things are what they are, and reality exists with its own characteristics and natural laws, whether we as humans have discovered them or not (Bhaskar, 1998; López \& Potter, 2005). However, the transitive view of human experience also acknowledges that our understanding and knowledge of the natural world are fallible and relative to our experiences, and therefore reality transcends human experience, thus transcendental realism (Bhaskar, 1998; López \& Potter, 2005).

In critical realism, "reality" is understood to be made up of multiple strata: the domain of the real, the domain of the actual, and the domain of the empirical (Bhaskar, 1998; Bhaskar \& Lawson, 1998). The domain of the real is the strata of natural reality, made up of the causal mechanisms and natural laws that provide the foundation and 
underpinning of the world. The domain of the actual is the full scope of human events and experiences of reality, both what a specific individual has experienced and all the experiences of other humans that any one individual would not necessarily be aware of. Finally, the domain of the empirical contains the specific experiences one individual has; the lived reality of a human where empirical data can be collected, but which is limited to only that one individual's interpretation and context.

There are two important points to make here in connecting this understanding of reality in critical realism to science and ultimately science education. One, this understanding of reality and human experience makes true that events which humans experience are not the full measure of reality. Things that have not been experienced and causal mechanisms that have not yet been discovered are still a key part of this understanding of reality (López \& Potter, 2005). Gravity does not exist because humans discovered this natural law, and the imperfect human understanding of gravity is not the sum of the real mechanism itself. Human understanding gives us ways to discuss and understand the natural world, but it is not exhaustive of all reality. Two, scientific exploration and experimentation in critical realism can be seen as both a search for the causal mechanisms and natural laws that make up lived reality, and an imperfect understanding of reality limited by human experience and social systems (Bhaskar \& Lawson, 1998; López \& Potter, 2005). Reality can be understood as a closed system, in that all the natural laws and causal mechanisms that make up the world, whether we know them or not, exist and interact in a system with each other. However, humans operate in an open social system, and scientific experimentation is an attempt to close that system to explore natural laws, but this is by nature susceptible to human and social interference.

Critical realism can then be seen as a philosophy that holds in tension the positivist assertion that there is a reality, the post-positivist stance that humans can attempt to uncover this reality but also acknowledge that human understanding will be flawed and contain both truth and error, and the postmodern understanding that experiences of reality are relative and must be considered within the social and physical context (Bhaskar, 1998; Bhaskar \& Lawson, 1998; López \& Potter, 2005). Like postmodern understandings of science, critical realism supports that scientific knowledge is a social process that is influenced by social pressures and is relative to the humans involved (López \& Potter, 2005; Yucel, 2018). However, critical realism also argues that this understanding of cultural and historical context in science does not also mean there is no shared reality or natural law to be discovered, an idea from wave one science study (Yucel, 2018). Humans engaging in scientific experimentation and exploration will sometimes be wrong, but empirical knowledge compiled across multiple human experiences, both in formal science settings and informal community settings, creates a collaborative accumulation of human knowledge of the domain of the real (Bhaskar, 1998; Forsyth, 2005; López \& Potter, 2005). Formal science can thus be seen as a rational and rigorous exploration of empirical experiences, refining our collective knowledge and human experiences of the domain of the actual (López \& Potter, 2005). Science educators are then tasked with both teaching what is believed to be true currently about the domain of the real and providing space for understanding the rational and critical aspects of human impact on science from the domains of the actual and the empirical. In this way, critical realism can operate as an ontology and epistemology of science education. 


\section{Science Education Across the Paradigms of Science Study}

\subsection{Positivistic Science Education}

Science education grounded in the positivist paradigm mirrors the wave one science study conception, focusing predominantly on teaching empirical science and logical inference. Students in this paradigm were taught that all science is a search for truth and objective fact, and no real discussion was given to the reality of scientists as humans with biases in their interpretations and decisions (Collins, 2015). School science was seen as a smallscale experience of real science, with significant investment from the federal government to see science curriculum written and implemented to teach students how to do "real" science (Yee \& Kirst, 1994). In the USA, the National Science Foundation was founded during this period of thought, and over $\$ 100$ million dollars were funneled through colleges and universities to develop science education curriculum and train teachers in providing these lessons to $\mathrm{K}-12$ students. Scientists in higher education were positioned as the experts of science curriculum development, and science education shifted from local and student interest driven curriculum to focus on a broader understanding of scientific principles and processes (Collins, 2015; Yee \& Kirst, 1994).

\subsection{Postmodern Science Education}

The paradigm shift from positivism to postmodernism in science education, like wave two science study, also showed a shift away from a search for objective "truth" and towards an emphasis on interpretation, as well as more negative views of scientists and their work. However, it could be argued that this shift in paradigm for science education, and possibly science study itself, would be better positioned in the ongoing argument between positivism and postmodernism, instead of as being a movement explicitly to postmodernism (Makenzie, et al., 2014). A focus on scientific processes and content knowledge does not disappear, and in fact the increase in standardized assessment during wave two seems to further emphasize these elements of science education.

\subsubsection{Lingering Positivist Ideals}

In American education policy, the 1983 report “A Nation at Risk" highlights early concerns in this period as positivist grounding for science education was fading and the focus was shifting to a fear of the USA falling behind other countries in areas of science and technology. In education there was a concern that overemphasis on "elite" students had resulted in an overall reduction of scientific knowledge, and a call was made for science education to refocus on the needs of all students (Kormondy, 1985). Additionally, there was a shift in perspective on the science teacher, with a call for more "qualified" teachers to teach math and science curriculum, asking teachers to be science experts themselves before teaching others (Kormondy, 1985; NSBC, 1983). Later legislation in this paradigm shift, such as No Child Left Behind (NCLB) Act of 2001 (2002), continued this focus on "qualified" teachers, though the definition has shifted or been undefined at different points in time. Oversight and accountability moved increasingly to the federal government, with less local and state control of standards for education and qualifications of teachers. In many ways, 
education policy continues to focus on positivist ideas such as shared standards for curriculum, objective assessments of knowledge, and judgments of quality for teaching based on credentials and performance.

In science education broadly, continued positivist practices that were the foundation of wave one science study can be seen in the focus on preparation for assessment due to educational policy requirements. Preparing students for testing impacts the types of content teachers focus on as well as the classroom practices they use (Hollingworth, 2007; Pedulla et al., 2003; Solley, 2007), and in science specifically this often results in a focus on objective science facts that can be easily assessed. Content knowledge focused on laws of science or evidence pulled from data takes precedence in this focus, though the goal is not so much discovery and understanding of scientific principles as it is memorization of key points and identification of ideas (Gilbert, 2013; Pedulla et al., 2003; Solley, 2007). Some aspects of science teaching align with this focus, such as pre-packaged lab experiment kits (sometimes known as lab-in-a-box) that set students up to "find" the already known "right" answer (Collins, 2015; Furtak, 2006; Hofstein \& Lunetta, 2004). Inquiry and experimentation in the classroom are therefore not a micro experience of real science, but rather a mimicry of real science that often fails to meaningfully engage students in true exploration and decision making (Bevins \& Price, 2016; Gilbert, 2013).

\subsubsection{Increasing Postmodern Ideals}

However, science teaching practice did not always follow this focus on standardization and positivist or post-positivist conceptions of "truth" and instead can be seen to shift further to postmodern techniques, the changes implied in wave two understandings of science. The US National Research Council (1992) published a summary on their perception of science education standards that claimed a postmodern view of the nature of science. This same orientation can be seen in much of the research and curriculum development scholarship since that time (Mackenzie et al., 2014; Mansour, 2009). Science education was refocused on the interests of students and local populations, while still engaging in the broader understandings of science content and inquiry processes. Students were taught the understood evidence of science, but new emphasis was given to bias and interpretation in science, and "facts" were now presented as questionable depending on how they were originally supported (Mansour, 2009).

A shift in pedagogy and instructional practice in science education to align with the postmodern approach can also be seen in specific instructional strategies emphasizing reasoning to support scientific claims such as Claims-Evidence-Reasoning assignments (CERs; Meacham, 2017; McNeill \& Martin, 2011), or emphasizing critical discourse in Socratic seminars and debates (Chowning, 2009; Griswold et al., 2017). These two strategies in particular are of interest in this conversation due to their close alignment with postmodern teaching strategies, emphasizing student development of their own knowledge and their ability to share this knowledge with others. However, these two are also of interest as they highlight one of the limitations of a strong postmodernist approach to education, in that there is little focus on being factually correct in the way these activities are typically implemented in the classroom.

For example, CERs ask students to make a claim, support their claim with evidence, and provide their reasoning or thought process (Meacham, 2017; McNeill \& Martin, 2011). However, the way these assignments and associated rubrics are usually designed, it is absolutely possible for a student to make a claim that is actually false 
scientifically, present evidence that supports their particular claim (and ignore other evidence or accepted scientific facts), and provide their reasoning on why this evidence supports their claim. While a science teacher can catch this error and make corrections about misconceptions, the form of the assignment itself emphasizes personal perceptions of evidence and reasoning over developed and accepted scientific evidence and fact. Often no instructions are given to cite scientific sources in the assignment, and no space on the rubrics for these assignments provides any evaluation of the actual scientific facts associated with the topic. Socratic seminars in science sometimes fall to a similar failing, especially when rubrics for grading students in Socratic seminars are focused only on participation and students asking or answering questions (Chowning, 2009; Griswold et al., 2017), not on being factually accurate or correct in their answers, or providing evidence connected to known scientific knowledge. Well-designed Socratic seminars can help students build their argumentation skills and build consensus among the class on a topic of discussion, but often this is not the way these activities are being implemented in science classrooms.

The de-emphasis on positivist conceptions of science education has arguably gone too far in these examples, setting up the situations discussed in postmodern paradigm science denial where each individual's opinion and evidence are rated as being equally valid in comparison to scientific evidence supported by best practices in scientific inquiry. That is not to say these particular assignments have created the anti-science problem in modern society. Rather, as said earlier, the argument here is that these assignments are developed and implemented within the broader epistemology of postmodern science education, which has arguably moved away from a grounding in scientifically supported evidence and therefore provides the framework for science denial and mistrust (Mackenzie et al., 2014).

\subsection{Shifting to Critical Realist Science Education}

My discussion so far implies further work for science education in the current paradigm shift: developing a foundational critical scientific literacy in all students, while also allowing for those interested in science as a profession to develop their knowledge towards post-secondary goals. Modern science education benefits from an epistemological frame that allows for both a focus on objective truths and knowledge of science (traditionally wave one positivism) and a realization of the human impacts and influences on scientists and the social role of science (traditionally postmodernism in wave two science). In developing an understanding of this paradigm of science education, I argue that critical realism can serve as a framework for what and how educators can teach science. Critical realism is uniquely designed to provide grounding for the existence of multiple experiences of reality in science, while still holding the premise that there are causal mechanism and natural order that underlie our human experience that is the ultimate goal of scientific exploration (Bhaskar, 1998; Yucel, 2018). Modern science education needs to hold true that empirical evidence and logical reasoning matter, while also acknowledging interpretation of evidence and reasoning is human dependent and not neutral by nature. Critical realism as a paradigm shift is one way of supporting these two seemingly contradictory statements that may provide a meaningful framing for those engaged in the work of science education, especially when arguing for changes in policy or seeking support from administration. 


\section{Critical Realism Applied to Science Education}

In discussing wave three science education, Collins (2015) argues that science educators should teach students to value scientific expertise while also holding it accountable. He positions science as a calling that must be understood as a collective process of inquiry and exploration, with professional standards and transparent practices. Unethical or biased science is presented as "bad" science, and the focus in education is understanding what "good" science is and how the field of science at large works together to pursue discovery and achieve consensus (Collins, 2015). Weinstock et al. (2017) argue that science education is currently not effectively teaching students how to do science, but rather mimes science. Science education, in their thinking, should instead focus on critical scientific literacy: teaching students about collaboration and the search for knowledge that is connected to real world problems and decision making. For instance, instead of presenting canned lab assignments as if they are a model of real science and inquiry, I posit that science education grounded in critical realism asks teachers to provide students a better understanding of what the work of science really is in professional practice, and allow students to experience failure, unknown answers, requirements for critical thinking, and collaborative engagement with science. The challenge in a lab assignment often becomes one of time, as the need to move quickly through a lab and the related written report has to be balanced with time for reflection and critical thinking. Science educators should consider creating at least one lab experience in a class that gives students permission to ask questions and not know answers, without resulting in a "failing" grade. Unlike prior conceptions of science education, this framing of science education would be positioned as a systematic process of discovery and inquiry that relies on professional collaboration and transparent practices in working with and in society, instead of a search of objective "truth" (Collins, 2015; Weinstock et al., 2017).

This paradigm shift in science education focuses on the balance between a search for positivist objective truth or scientific knowledge on one side, and an understanding of postmodern human lived experiences and social impact of scientific discovery on the other side. However, critical realism as a framework for science education can also guide the conversation beyond the push and pull of positivism and postmodernism, and provide grounds for important ongoing conversations about scientific knowledge and expertise, and how students should value and recognize different forms of knowledge (Bhaskar \& Lawson, 1998; López \& Potter, 2005; Yucel, 2018). Understanding that humans all live in the domain of the empirical in any given moment, and that the domain of the actual can be understood as collective experiences of the world that are connected to but not exhaustive of the domain of the real, science is positioned as a process and profession that seeks to understand the natural world in the domain of the real, though always imperfectly as we are only able to pull from our collective empirical experiences in the domain of the actual (Bhaskar, 1998).

Beyond the imperfect nature of human knowledge and experience, critical realism also provides grounding for the understanding that human experiences in the domain of the empirical are going to be different due to context and place in time and space. Science that is driven only by one perspective or understanding of reality is therefore by nature going to be flawed. Science education in a framing of critical realism must provide an understanding for students that empirical exploration of science is always limited by human context and impacted by human behavior, but the underpinning of the domain of the real with natural laws and causal mechanisms still exists 
and functions with or without our human knowledge and discovery (Bhaskar, 1998; Forsyth, 2005).

Science grounded in critical realism engages in both empirical and lived experience research, collecting data on our own empirical experiences of reality as an individual and collecting data from across human experience of empirical events where possible to capture other lived experiences of reality (Forsyth, 2005). This clearly connects to the modern science perspective on collaborative inquiry and consensus building (Collins, 2015; Weinstock et al., 2017), but also goes beyond that initial argument to highlight community and cultural knowledge that should be a part of developing scientific knowledge in a critical realist conception of science (Forsyth, 2005; McKittrick, 2021). While inquiry-based learning and science inquiry broadly have become hallmarks of modern science education, there have been varying levels of success in implementation (Bevins \& Price, 2016; National Research Council, 2000). Critical realism as a framework for science education requires an understanding that the natural and social sciences are connected as spaces of human knowledge and experience, all of which represent imperfect but meaningful experiences of the natural world and mechanisms of reality (Bhaskar, 1998; McKittrick, 2021). Separating these aspects of human experience into silos and treating natural science as somehow more objective or removed from human experience than social science is a false dichotomy that no longer makes sense in a science education paradigm defined by critical realism. The understanding of experimentalism that humans can replicate a closed system in controlled study is not realistic, and critical realism provides a clear argument that human interaction will always impact understandings of the domain of the real (Bhaskar, 1998; Bhaskar \& Lawson, 1998).

Instead of seeking to teach students about science as objective truth or a systematic process of inquiry removed from the social world, science education now needs to engage in what Forsyth (2005) calls "hybrid science," an essential connection between formal scientific experimentation and the historical knowledge of communities and individuals that has been ignored or oppressed in the search for objective scientific truth (McKittrick, 2021). But in this often-postmodern presentation of the contextual nature of science and knowledge, critical realism also reminds us to not lose sight of the natural reality that does underpin all of human experience. As argued previously, humans did not create gravity when they put a name to it and reached consensus on its nature. And conversely, gravity in the current flawed human understanding of the natural principle is not the sum total of its real function and causal mechanisms. Our understanding of gravity neither makes it real or means it does not exist; our understanding is the collective consensus of human experience and empirical data, but gravity itself is not dependent on our understanding nor limited to what we know of it. Science educators can teach students what science currently believes to be true about gravity and its function, while acknowledging what we do not yet know about gravity and clarifying that this principle will be updated when the field knows more. In application, this could mean that when science educators are developing lessons on topics that relate to the local community (i.e., environmental concerns, public health, city infrastructure and development), they should consider inviting contributions from keepers of historical and community knowledge in addition to formal science experts. By diversifying who is considered an expert on a topic, science educators can guide their students in developing modern understandings of what it means to be an expert (Watson, 2020). 


\subsection{Teaching Science Grounded in Critical Realism}

Critical realist science education therefore needs to provide space for teaching both arbitrary and non-arbitrary science knowledge: what is currently known about the domain of the real from experiences and empirical data, and an understanding of experiences in the domain of the actual and human impacts on developed knowledge (Matthews, 1998, 2012; Scott, 2010). Our modern scientific practices and processes for inquiry and the understanding of the natural world reached through professional study and consensus should be presented as non-arbitrary knowledge (Collins, 2015; Scott, 2010). Human impact on science and the process of discovery and developing or new understandings of the natural and social world should be presented as arbitrary knowledge, subject to update and critique as knowledge is developed and adjusted over time and across experts and contexts (Forsyth, 2005; Scott, 2010). Non-arbitrary knowledge would be seen as the foundational component of the science education curriculum, while arbitrary knowledge is taught with an understanding of the changing and social nature of science impacted by human decisions and social systems (Scott, 2010).

As the argument is for critical realism to function as a framework for modern science education, it follows that this understanding should align with the current understanding of the nature of science. Therefore, I am connecting critical realism as a framing for scienced education to the National Science Teaching Association (NSTA, n.d. and the Next Generation Science Standards (NGSS, 2014) both position the nature of science around eight principles or beliefs:

1. "Scientific Investigations Use a Variety of Methods;

2. Scientific Knowledge Is Based on Empirical Evidence;

3. Scientific Knowledge Is Open to Revision in Light of New Evidence;

4. Science Models, Laws, Mechanisms, and Theories Explain Natural Phenomena;

5. Science Is a Way of Knowing;

6. Scientific Knowledge Assumes an Order and Consistency in Natural Systems;

7. Science Is a Human Endeavor; and

8. Science Addresses Questions About the Natural and Material World.'

Some of these principles can be understood as elements of the non-arbitrary science curriculum, while some might be better argued as components of the arbitrary science curriculum, though this distinction is not perfect (see Table 1). For instance, elements of principle 8 might be considered non-arbitrary, in addressing inquiry about the natural world. However, my primary argument is that these accepted principles of the nature of science in current science education practice can align with critical realism as an epistemology of science education in prioritizing the teaching of non-arbitrary scientific knowledge and processes, and the arbitrary human impact and changing understandings of science.

\subsection{Non-Arbitrary Knowledge: Seeking the Domain of the Real through the Empirical}

Non-arbitrary knowledge in science education is historically the foundation of the science curriculum, especially in positivist paradigm science education. This knowledge includes both the processes of inquiry and experimentation in science, and the foundational laws, 
Table 1 Non-arbitrary and arbitrary principles of the nature of science

\begin{tabular}{ll}
\hline Non-arbitrary science principles & Arbitrary science principles \\
\hline $\begin{array}{l}\text { Defined as scientific practices, inquiry processes, } \\
\text { and shared understandings of the natural world }\end{array}$ & $\begin{array}{c}\text { Defined as human impact on science and developing } \\
\text { or new understandings of the natural and social } \\
\text { world }\end{array}$ \\
$\begin{array}{ll}\text { Scientific Investigations Use a Variety of Methods } \\
\text { Scientific Knowledge Is Open to Revision in Light of } \\
\text { New Evidence; }\end{array}$ \\
$\begin{array}{l}\text { Scientific Knowledge Is Based on Empirical } \\
\text { Evidence }\end{array}$ \\
$\begin{array}{l}\text { Science Is a Way of Knowing; } \\
\text { Explain Natural Phenomena; }\end{array}$ \\
$\begin{array}{l}\text { Scientific Knowledge Assumes an Order and Con- } \\
\text { sistency in Natural Systems; }\end{array}$ & $\begin{array}{c}\text { Science Addresses Questions About the Natural and } \\
\text { Material World }\end{array}$ \\
\hline
\end{tabular}

Nature of science principles from NSTA (n.d.), non-arbitrary and arbitrary knowledge definitions adapted from Scott (2010)

mechanisms, models, etc. that underpin our current understanding of the natural world. Teaching non-arbitrary knowledge under critical realism paradigm science might be best understood as teaching critical scientific literacy, as students should have an understanding of the work of science including experimentation and research, writing about scientific inquiry, reading and referencing scientific texts, presenting on developing understandings and results of inquiry, and collaborating with others to reach consensus and share knowledge (Bevins \& Price, 2016; Gilbert, 2013; Mody, 2015). While inquiry in science education is by no means a new conception, recent critiques of inquiry in the science classroom have pointed out the tendency to reduce inquiry to linear rules and processes divorced from critical thinking and creativity (Bevins \& Price, 2016; Gilbert, 2013). This reduces the true nature of scientific inquiry in 'real' science to a mimicry of science, a critique of postmodern science education that we are trying to move past in a critical realism framing (Collins, 2015; Weinstock et al., 2017). There is value in helping students understand the content knowledge of science, including the current understanding of natural laws and causal mechanisms that make up the domain of the real (Bhaskar, 1998; Scott, 2010), but positioning this with more connections to the real work of science in inquiry driven by creative and critical thinking is an important shift in teaching practice.

Instead of always engaging students in an inquiry project or lab where the end result is already known, consider what would change if science educators designed inquiry projects around questions that are not yet answered in science. How could students use current understandings of science and the natural world to explore and imagine what might be possible in an undefined problem, and how could students explore or test these unknowns in a true scientific inquiry process (some resources on these unknowns in science: Cahn, 2020; Gottlieb-Cohen, 2019; Haloupek, 2019). To be clear, I am not arguing this approach should replace all inquiry projects in science, but instead that this could be included as a single project or module on "the search for the unknown in science," or an extension activity added on to other well-defined projects. Additionally, how could the science and inquiry curriculum be more directly connected to the work of science in tasks like acquiring needed materials, collaborating and networking with experts, or dealing with failure or rejection and looking for new avenues or resources for next steps (Mody, 2015). Developing authentic inquiry in science classrooms is not easy, and it is not particularly supportive 
of the traditional models of education delivery and assessment (Bevins \& Price, 2016; Gilbert, 2013), but I argue engaging in authentic inquiry is needed for students to truly develop critical scientific literacy and an understanding of non-arbitrary science in pursuit of the domain of the real.

\subsection{Arbitrary Knowledge: Understanding the Domain of the Actual}

In considering how to best teach non-arbitrary science in the classroom, science educators must also consider how to infuse arbitrary knowledge and thinking into this same curriculum; not as a side component or extension of a lesson, but as an integral part of developing critical scientific literacy and an understanding of the nature of science grounded in critical realism (Bhaskar, 1998; Scott, 2010). While science has a series of tools and processes that are generally used in inquiry, science is also by nature messy and embraces uncertainty (Mody, 2015). Students need to learn how to acknowledge what they know and what they do not yet know without penalty, providing evidence beyond their own experience to support their thinking and develop consensus, or adjust their understanding with new knowledge. Current science education practices discussed previously like Claims, Evidence, Reasoning assignments (CERs; Meacham, 2017; McNeill \& Martin, 2011), and Socratic seminars (Chowning, 2009; Griswold et al., 2017) are designed to support these components of student learning. However, without connecting these assignments to non-arbitrary knowledge, such as requiring students to cite scientific sources that support their arguments, and subjecting their understanding and argument to review against shared knowledge, this practice is still a mimicry of scientific practice in the real world.

For CERs, think about how the student experience might change if a requirement is added for scientific citations to the evidence component of the rubric, and the claim component is subject to review against shared knowledge of the concept of interest. To balance the arbitrary and non-arbitrary aspects of science education, science educators need to emphasize scientific fact and shared knowledge in the development of critical thinking and crafting arguments. The goal of CERs is at least partially to understand how arguments are built with a claim and provided evidence, but more structured guidance for students should be provided to apply critical scientific literacy to what evidence is selected and how reason is applied to the claim. For Socratic seminars, valuing the process of critique and participation in the conversation is important and already an integral part of the process. However, students should also be expected to provide concrete evidence to support their claims, and the evidence should either be acknowledged as limited to individual empirical experience, or be presented as developed from scientific expertise using a reference to existing sources. The leader of the Socratic seminar should also be prepared to critique and push for clarity in argumentation, and to consistently summarize and update the shared knowledge of the topic throughout the seminar to model scientific conversations. Arbitrary knowledge in science does not exist in a vacuum disconnected from non-arbitrary knowledge, and connecting these aspects of the curriculum is a key component of the development of critical realism as an epistemology of science education.

Curriculum on arbitrary knowledge in critical realism paradigm science education should also engage in the work of decolonizing what is known about science, and considering what is truly non-arbitrary knowledge and what should be better understood as arbitrary ways of knowing that are dependent on human activity and context. Science education in positivist paradigm science, and often in postmodern paradigm science, rarely presented other ways of knowing and understanding science beyond the European or 
western model (Aikenhead \& Ogawa, 2007; McKittrick, 2021; Gilbert, 2013; Harding, 2016). Some aspects of the curriculum that we might consider non-arbitrary in traditional science would be better understood in a decolonizing lens as inherently connected to European knowledge development, grounded in colonialism and/or capitalism (Gilbert, 2013; McKittrick, 2021). If you are planning a lesson or module on a local issue for students to explore, think about what might change if you invited local or historical knowledge experts to the conversation in addition to traditional science experts and resources. Critical realism argues for an understanding of science and epistemology that considers context and human impact on what is known, and this is directly applicable to even seemingly non-arbitrary aspects of science (Bhaskar, 1998; Scott, 2010). We can only attempt an understanding of the domain of the real through development of shared knowledge in the domain of the actual, and that is not limited to only one version of truth or way of knowing. Experts from multiple ways of knowing across the domain of the actual should be given space in developing our understanding of the natural world in exploring the domain of the real in science education grounded in critical realism.

\section{Conclusion}

Science and science education have shifted throughout history in response to changing philosophies of how we can know the natural world and develop scientific knowledge. From the positivism dominant wave one to the postmodern critiques in wave two, science education has responded with a constant focus on trying to effectively teach students about the natural world and the human derived laws and principles that define our understanding of science. In this article, I have argued for the place of critical realism as a paradigm for wave three science education, providing a framework that can hold in tension the goal of discovering what is "real" about the natural world with an awareness of the human and social impact on our understanding in the actual world. Additionally, I have presented specific examples of the application of critical realism as a framework for science education, connecting the tenets of critical realism to principles of the nature of science and teaching strategies such as inquiry learning, CERs, and Socratic Seminars. For those whose job it is to teach, critical realism is presented as a way of thinking about the science curriculum at multiple levels, including recommendations on how to teach the nature of science in both arbitrary and non-arbitrary forms and support students in developing a critical scientific literacy and understanding of the "real" work of science. This is not presented as a completely new way of teaching science, but instead is intended as a new framing for talking about and evaluating science education practice. In the continuous shift of paradigms and practice, critical realism provides a model for science education that values both nonarbitrary and arbitrary content in science, and guides educators to prioritize both aspects of the curriculum and ensure the direct connections between the two sides are made clear for students.

Future research could explore curriculum development grounded in critical realism and study the effectiveness of curriculum designed in this way. Additionally, explorations of the student understandings of science under this paradigmatic conception would help test the usefulness of this idea in practice. Teacher educators and those providing professional development should also consider what wave of science education they are supporting, and whether critical realism might give them an additional lens to think about their materials and support for teachers. Finally, curriculum and science education materials provided to 
students could be evaluated, considering what version of science is being taught in current curriculum and where other elements of knowing in science can be infused into the existing curriculum to broaden our students' understanding of what is "real" about science.

Data availability Not applicable

Code Availability Not applicable

\section{Declarations}

Conflict of Interest The author declares no conflict of interest.

\section{References}

Aikenhead, G. S., \& Ogawa, M. (2007). Indigenous knowledge and science revisited. Cultural Studies of Science Education, 2(3), 539-620. https://doi.org/10.1007/s11422-007-9067-8

Beebeejaun, Y., Durose, C., Rees, J., Richardson, J., \& Richardson, L. (2015). Public harm or public value? Towards coproduction in research with communities. Environment and Planning. C, Government \& Policy, 33(3), 552-565. https://doi.org/10.1068/c12116

Bevins, S., \& Price, G. (2016). Reconceptualising inquiry in science education. International Journal of Science Education, 38(1), 17-29. https://doi.org/10.1080/09500693.2015.1124300

Bhaskar, R. (1998). The logic of scientific discovery. In M. Archer, R. Bhaskar, A. Collier, T. Lawson, \& A. Norrie (Eds.), Critical realism: Essential readings. Taylor and Francis.

Bhaskar, R., \& Lawson, T. (1998). Introduction: Basic texts and developments. In M. Archer, R. Bhaskar, A. Collier, T. Lawson, \& A. Norrie (Eds.), Critical realism: Essential readings. Taylor and Francis.

Bloor, M. (2000). The South Wales Miners Federation, miners' lung and the instrumental use of expertise, 1900-1950. Social Studies of Science, 30(1), 125-140. https://doi.org/10.1177/030631200030001005

Brown, M. B. (2015). Politicizing science: Conceptions of politics in science and technology studies. Social Studies of Science, 45(1), 3-30. https://doi.org/10.1177/0306312714556694

Brush, S. G. (1989). History of science and science education. Interchange, 20(2), 60-70. https://doi.org/10. 1007/BF01807048

Cahn, L. (2020). 15 science mysteries no one has figured out. Reader's Digest. https://www.rd.com/list/scien ce-mysteries-no-one-has-figured-out/. Accessed 3 Dec 2021

Chowning, J. T. (2009). Socratic seminars in science class: Providing a structured format to promote dialogue and understanding. Science Teacher (Normal, Ill.), 76(7), 36-41.

Collins, H. (2014). Are we all scientific experts now? Polity.

Collins, H. (2015). Can we teach people what science is really like? Science Education, 99(6), 1049-1054.

Collins, H. M., \& Evans, R. (2002). The third wave of science studies: Studies of expertise and experience. Social Studies of Science, 32(2), 235-296. https://doi.org/10.1177/0306312702032002003

Collins, H. M., \& Evans, R. (2003). King Canute meets the beach boys: Responses to the third wave. Social Studies of Science, 33(3), 435-452. https://doi.org/10.1177/03063127030333007

DeBoer, G. E. (1991). A history of ideas in science education: Implications for practice. Teachers College Press.

Every Student Succeeds Act, 20 U.S.C. § 6301 (2015). https://www.congress.gov/bill/114th-congress/senate-bill/1177. Accessed 3 Dec 2021

Forsyth, T. (2005). Critical realism and political ecology. In J. López \& G. Potter (Eds.), After postmodernism: An introduction to critical realism. Bloomsbury Publishing.

Funke, J. (2017). Citizen science and psychology: An evaluation of chances and risks. Heidelberger Jahrbücher Online, 2, 5-18. https://doi.org/10.17885/heiup.hdjbo.2017.0.23690

Furtak, E. M. (2006). The problem with answers: An exploration of guided scientific inquiry teaching. Science Education, 90(3), 453-467. https://doi.org/10.1002/sce.20130

Gauchat, G. (2015). The political context of science in the United States: Public acceptance of evidencebased policy and science funding. Social Forces, 94(2), 723-746. https://doi.org/10.1093/sf/sov040

Gilbert, A. (2013). Courageous pedagogy: Enacting critical science education. Information Age Publishing. 
Gil-Pérez, D., Guisasola, J., Moreno, A., Cachapuz, A., De Carvalho, A. M. P., Torregrosa, J. M., ... \& Gallego, R. (2002). Defending constructivism in science education. Science \& Education, 11(6), 557-571. https://doi.org/10.1023/A:1019639319987

Good, R. (1993). Editorial: The slippery slopes of postmodernism. Journal of Research in Science Teaching, 30(5), 427.

Gottlieb-Cohen, S. (2019). Science means not knowing. Scientific American. https://blogs.scientificameri can.com/observations/science-means-not-knowing/. Accessed 3 Dec 2021

Griswold, J., Shaw, L., \& Munn, M. (2017). Socratic seminar with data: A strategy to support student discourse and understanding. The American Biology Teacher, 79(6), 492-495. https://doi.org/10.1525/abt. 2017.79.6.492

Grundmann, R. (2017). The problem of expertise in knowledge societies. Minerva, 55(1), 25-48.

Haloupek, N. (2019). 12 common things science still hasn't figured out. Mental Floss. https://www.menta lfloss.com/article/567856/common-things-science-hasnt-figured-out. Accessed 3 Dec 2021

Harding, S. (2016). Latin American decolonial social studies of scientific knowledge: Alliances and tensions. Science, Technology \& Human Values, 41(6), 1063-1087. https://doi.org/10.1177/0162243916 656465

Hofstein, A., \& Lunetta, V. N. (2004). The laboratory in science education: Foundations for the twenty-first century. Science Education, 88(1), 28-54. https://doi.org/10.1002/sce.10106

Hollingworth, L. (2007). Five ways to prepare for standardized tests without sacrificing best practice. The Reading Teacher, 61(4), 339-342. https://doi.org/10.1598/RT.61.4.7

Houghton, D. P. (2008). Positivism 'vs' postmodernism: Does epistemology make a difference? International Politics, 45(2), 115-128. https://doi.org/10.1057/palgrave.ip.8800222

Jasanoff, S. (2009). The fifth branch: Science advisers as policymakers. Harvard University Press.

Kormondy, E. J. (1985). Science education: The challenge of the 80s. The American Biology Teacher, 47(7), 402-409. https://doi.org/10.2307/4448108

Kuhn, T. S. (1970). The structure of scientific revolutions (2nd ed.). University of Chicago Press.

López, J., \& Potter, G. (2005). After postmodernism: An introduction to critical realism. A\&C Black.

Mackenzie, J., Good, R., \& Brown, J. R. (2014). Postmodernism and science education: An appraisal. In M. Matthews (Ed.), International Handbook of Research in History, Philosophy and Science Teaching. Springer.

Mansour, N. (2009). Science-technology-society (STS): A new paradigm in science education. Bulletin of Science, Technology \& Society, 29(4), 287-297. https://doi.org/10.1177/0270467609336307

Marks, J. M. (1984). Science and the making of the modern world. Heinemann.

Marsden, D., \& Littler, D. (1999). A dialectical approach to consumer research: Beyond positivism and postmodernism. In B. Dubois, T. M. Lowrey, L. J. Shrum, \& M. Vanhuele (Eds.), E-European Advances in Consumer Research (4th ed.). Association for Consumer Research.

Matthews, M. R. (1998). In defense of modest goals when teaching about the nature of science. Journal of Research in Science Teaching, 35(2), 161-174. https://doi.org/10.1002/(SICI)1098-2736(199802) 35:2\%3C161::AID-TEA6\%3E3.0.CO;2-Q

Matthews, M. R. (2012). Changing the focus: From nature of science (NOS) to features of science (FOS). InAdvances in nature of science research (pp. 3-26). Springer.

McKittrick, K. (2021). Dear science and other stories. Duke University Press.

McNeill, K. L., \& Martin, D. M. (2011). Claims, evidence, and reasoning. Science and Children, 48(8), 52-56.

Meacham, B. (2017). Implementing the claim, evidence, reasoning framework in the chemistry classroom. Chemical Education Xchange. https://www.chemedx.org/article/implementing-claim-evidence-reasoningframework-chemistry-classroom. Accessed 3 Dec 2021

Mody, C. C. (2015). Scientific practice and science education. Science Education, 99(6), 1026-1032. https:// doi.org/10.1002/sce. 21190

Mumby, D. K. (2004). Discourse, power and ideology: Unpacking the critical approach. In D. Grant, C. Hardy, C. Oswick, N. Phillips, \& L. L. Putnam (Eds.), The Sage Handbook of Organizational Discourse. Sage Publications.

National Commission on Excellence in Education. (1983). A nation at risk: The imperative for educational reform. The Elementary School Journal, 84(2), 113-130.

National Research Council. (1992). National science education standards: A sampler. National Committee on Science Education Standards and Assessment, National Research Council.

National Research Council. (2000). Inquiry and the national science education standards: A guide for teaching and learning. National Academies Press.

National Science Board Commission (NSBC). (1983). Educating Americans for the 21st century. The National Science Board 
National Science Teaching Association. (n.d.). Position statement: Nature of science. https://www.nsta.org/ nstas-official-positions/nature-science. Accessed 3 Dec 2021

Next Generation Science Standards. (2014). Connections to the nature of science. https://ngss.nsta.org/ NSConnectionsFull.aspx. Accessed 3 Dec 2021

No Child Left Behind (NCLB) Act of 2001, (2002). Pub. L. No. 107-110, § 101, Stat. 1425.

Owens, S. (2011). Three thoughts on the Third Wave. Critical Policy Studies, 5(3), 329-333. https://doi.org/ $10.1080 / 19460171.2011 .606307$

Pedulla, J. J., Abrams, L. M., Madaus, G. F., Russell, M. K., Ramos, M. A., \& Miao, J. (2003). Perceived effects of state-mandated testing programs on teaching and learning: Findings from a national survey of teachers. Boston College, National Board of Educational Testing and Public Policy. www.bc.edu/ research/nbetpp/statements/nbr2.pdf. Accessed 3 Dec 2021

Pratt, A. C. (1995). Putting critical realism to work: The practical implications for geographical research. Progress in Human Geography, 19(1), 61-74. https://doi.org/10.1177/030913259501900104

Pyenson, L., \& Sheets-Pyenson, S. (1997). The Norton history of science in society. Norton.

Reed, M. (2011). Critical realism in critical management studies. In M. Alvesson, T. Bridgman, \& H. Willmott (Eds) The Oxford handbook of critical management studies. https://doi.org/10.1093/oxfordhb/ 9780199595686.013 .0003

Sarathchandra, D., \& Haltinner, K. (2020). Trust/distrust judgments and perceptions of climate science: A research note on skeptics' rationalizations. Public Understanding of Science, 29(1), 53-60. https://doi. org/10.1177/0963662519886089

Scott, D. (2010). Education, epistemology and critical realism. Routledge.

Solley, B. A. (2007). On standardized testing: An ACEI position paper. Childhood Education, 84(1), 31-37. https://doi.org/10.1080/00094056.2007.10522967

Steinmetz, G. (1998). Critical realism and historical sociology: A review article. Comparative Studies in Society and History, 40(1), 170-186. https://www.jstor.org/stable/179393. Accessed 3 Dec 2021

Watson, J. C. (2020). Expertise: A philosophical introduction. Bloomsbury Publishing.

Weinstock, M., Kienhues, D., Feucht, F. C., \& Ryan, M. (2017). Informed reflexivity: Enacting epistemic virtue. Educational Psychologist, 52(4), 284-298. https://doi.org/10.1080/00461520.2017.1349662

Wynne, B. (2003). Seasick on the third wave? Subverting the hegemony of propositionalism: Response to Collins \& Evans (2002). Social Studies of Science, 33(3), 401-417. https://doi.org/10.1177/03063 127030333005

Yee, G., \& Kirst, M. (1994). Lessons from the New Science Curriculum of the 1950s and 1960s. Education and Urban Society, 26(2), 158-171. https://doi.org/10.1177/0013124594026002004

Yucel, R. (2018). Scientists' ontological and epistemological views about science from the perspective of critical realism. Science \& Education, 27(5), 407-433. https://doi.org/10.1007/s11191-018-9983-X

Publisher's Note Springer Nature remains neutral with regard to jurisdictional claims in published maps and institutional affiliations. 